\title{
Degradation kinetics of anthocyanin extracted from roselle calyces (Hibiscus sabdariffa)
}

\author{
Maripillai Munusamy Pragalyaashree*, Deivanayagame Tiroutchelvame, Siddant Sashikumar \\ Department of Food Processing and Engineering, Karunya Institute of Technology and Sciences, Coimbatore, India.
}

\section{ARTICLE INFO \\ Received on: 26/06/2018 \\ Accepted on: 8/10/2018 \\ Available online: $30 / 11 / 2018$}

\section{Key words:}

Hibiscus sabdariffa (Roselle), anthocyanin, optimization, calyx, ethanol extraction, kinetics study, half-life period.

\begin{abstract}
Roselle calyces (Hibiscus sabdariffa) pigment contains an inexpensive source of anthocyanins, which is used as a natural colorant in food preparation instead of artificial colors. Hence, a study was carried out to extract anthocyanin from roselle calyces using acidified ethanol. The pigment stability during storage under different temperature conditions was also investigated. Kinetics study of the roselle extract was conducted to find out the degradation rate. It was concluded that the pigment stored in an amber bottle under refrigerated conditions showed least degradation rate with a $k$ value of 0.0017 , followed by the pigment stored in a transparent bottle under refrigerated conditions with a $k$ value of 0.0025 . The highest degradation rate was found when the pigment was stored in the transparent bottle at $40^{\circ} \mathrm{C}$ under light with a $k$ value of 0.0055 . The half-life periods of the pigment extract stored in amber bottle and transparent bottle under refrigerated condition $\left(10^{\circ} \mathrm{C}\right)$, dark and light condition at $40^{\circ} \mathrm{C}$ were $407.73,277.25,223.59$, 138.62, 147.47, and 126.02 days, respectively. From the results of the experiments, it was found that the roselle calyces (Hibiscus sabdariffa) is a potential source of natural anthocyanin which can be used as a natural colorant in various food formulations.
\end{abstract}

\section{INTRODUCTION}

Anthocyanin is a type of bioactive phenolic compound, which is responsible for the red, blue, and purple color of plants. This bioactive compound improves the sight acuteness, antioxidant capacity, controlling Type II diabetes, reduction of coronary heart disease, and prevention of cancer (Peleg et al., 2015). Apart from their strong biological activities, the brilliant colors confirm their use as natural dye instead of artificial colorants in foods. Since the color is regarded as the most appealing criteria for consumer preference. Artificial colors are added to food, beverages, desserts, candy, and baked foods to get stability and uniformity but they are carcinogenic in nature. The use of natural additives as food colorant is trending in the global market now-a-days. The anthocyanin compounds can be extracted from many of the fruits, vegetables, and flowers and found to be inexpensive too.

"Corresponding Author

M. M. Pragalyaashree, Department of Food Processing and Engineering, Karunya Institute of Technology and Sciences, Coimbatore, India. E-mail: pragalyaashree@karunya.edu
Roselle (Hibiscus sabdariffa L.) belongs to Malvaceae family is a tropical plant and is a native of West Africa, which is now cultivated widely throughout the tropic and sub-tropic countries such as Sudan, China, Thailand, Egypt, Mexico, and West India (Plotto et al., 2004). In India, roselle is cultivated for vegetable fibers, especially in the Ganges delta region. Though it possesses edible and medicinal uses, it is not considered as an economic product (Patel, 2014). Since the roselle extract is rich in anthocyanin, the dried sepals and calyces are used in the preparation of cold beverages and hot drink after infusion. $\mathrm{Du}$ and Francis (1973) identified delphinidin-3-O-sambubioside (Dp-samb) and cyanidin-3-O-sambubioside (Cy-samb) as the major anthocyanin present in hibiscus. Delphinidin 3-glucoside and cyanidin 3-glucoside are regarded as minor pigments. It was agreed that $\mathrm{Dp}$-samb is the most abundant anthocyanin present in the calyces of roselle (Borras-Linares et al., 2015).

Anthocyanins, like other food color, are unstable in nature. The stability of the roselle anthocyanins depends on a combination of various factors, including temperature, $\mathrm{pH}$, the structure of anthocyanins, and light. Anthocyanins belong to a larger group of polyphenols, the flavonoids, which are able to 
absorb both UV and visible light. Stability of anthocyanin gets affected at an elevated temperature, which induces polymerization of monomeric anthocyanins and resulting in the browning of fruit juices and decreases the quality and consumer acceptance (Kirca and Cemeroglu, 2003).

Keeping in view, the importance of anthocyanin as a natural colorant in food products, a study was carried out to extract color from the calyces of roselle using acidified ethanol as solvent at different $\mathrm{pH}$, temperature, and time of extraction. The kinetics of pigment degradation during storage was also investigated.

\section{MATERIALS AND METHODS}

\section{Plant material}

The roselle calyx was brought from the field located at Tadepalligudem of Andhra Pradesh. Since roselle belongs to the family Malvaceae, the fresh calyx may contain mucilage (a polysaccharide) which plays a role as a resistance to extract anthocyanin; hence, drying of the calyx was done. The calyx was shade dried for 5-10 days and shelled manually to remove the seeds. This enables easy extraction of the pigment from roselle. The dried roselle calyx was then grounded to powder to increase the surface area of the calyx for an efficient extraction of the red roselle pigment.

\section{Reagents}

All the chemicals used were of analytical grade and purchased from Precision Scientific Company, Coimbatore and were used as such.

\section{Extract preparation}

Ground roselle calyx $(0.5 \mathrm{~g})$ was taken in five separate containers and mixed with solvents. The combination of different solvent is absolute ethanol, absolute ethanol acidified with $1.5 \mathrm{~N}$ $\mathrm{HCl}$, absolute ethanol acidified with $1 \mathrm{~N} \mathrm{HCl}$, absolute ethanol acidified with $1 \%$ citric acid (CA), and absolute ethanol acidified with $2 \% \mathrm{CA}$. The volume of taken solvent is five times the volume of the sample, i.e., in the ratio of 1:5. The solvents were acidified with the acid solution in the ratio of $85: 15$.

The samples were then kept in the incubator shaker for 2 hours under room temperature. The samples were removed and filtered for the pigment extract. The residue on the filter paper is further used for the extraction of the pigment till the roselle sample became almost colorless. The total amount of anthocyanin extracted from the calyces was quantified by spectrophotometer using the following formula:

$$
\text { Total Anthocyanin }(\mathrm{mg} / 100 \mathrm{~g})=\frac{\mathrm{A}_{535 \mathrm{~nm}} \times \mathrm{DF} \times \mathrm{V} \times 100}{\mathrm{y} \times \mathrm{z} \times 55.9}
$$

where

$$
\begin{array}{ll}
A_{535 \mathrm{~nm}} & =\text { Absorbance at } 535 \mathrm{~nm} \\
\mathrm{DF} & =\text { Dilution factor } \\
V & =\text { Volume of the extract obtained } \\
y & =\text { Volume of extract taken } \\
z & =\text { Weight of the sample taken }
\end{array}
$$

The optimization of anthocyanin from the roselle calyces was done by using the best formula (absolute ethanol acidified with $1.5 \mathrm{~N} \mathrm{HCl})$ at different samples: solvent ratios $(1: 2-1: 7)$, time
(30-120 minutes), temperature $\left(30^{\circ} \mathrm{C}-60^{\circ} \mathrm{C}\right)$, and $\mathrm{pH}(1-6)$ of the extraction and quantified by spectrophotometric analysis.

\section{Optimization of extraction temperature}

The dried roselle calyx was taken in four different vessels (1.5 g each), absolute ethanol acidified with $1.5 \mathrm{~N} \mathrm{HCl}$ (85:15) was added, and total anthocyanins were determined before heating. It was exposed to different temperature of extraction viz., $30^{\circ} \mathrm{C}, 40^{\circ} \mathrm{C}, 50^{\circ} \mathrm{C}$, and $60^{\circ} \mathrm{C}$. The extracted samples were then kept in incubator shakers operating at different temperatures for 2 hours. The samples were collected and filtered. The residue on the filter paper is further used for the extraction of the pigment till the roselle sample becomes almost colorless.

\section{Optimization of extraction time}

To optimize the time of extraction, samples were exposed to different duration of time (30, 45, 60, 90, and 120 minutes) and heated at a different temperature. Anthocyanin content was determined before and after extraction.

\section{Determination of heat stability of anthocyanins}

For heat stability, $10 \mathrm{ml}$ of the extract was placed in a screw-capped test tubes ( $55 \mathrm{ml}$ capacity) and heated in a controlled water bath at $60^{\circ} \mathrm{C}, 70^{\circ} \mathrm{C}, 80^{\circ} \mathrm{C}, 90^{\circ} \mathrm{C}$, and $100^{\circ} \mathrm{C}$ for $30,45,60$, 75 , and 90 minutes. The tubes were cooled down immediately in an ice bath and total anthocyanins were determined. Retention value of anthocyanins was estimated using the following equation:

$$
\text { Retention } \%=\frac{\text { Total Anthocyanin after Heating }(\mathrm{mg} / 100 \mathrm{~g})}{\text { Total Anthocyanin before Heating }(\mathrm{mg} / 100 \mathrm{~g})} \times 100
$$

\section{Degradation kinetics of anthocyanins during storage}

Storage study was conducted to evaluate the stability of color under different storage environments $\left(4^{\circ} \mathrm{C}\right.$ and $\left.40^{\circ} \mathrm{C}\right)$ under light and dark room, by filling it in amber colored and transparent bottles for 7 days. The bottles were kept airtight to prevent oxidation of the pigment. The kinetics of degradation was studied when exposed to different physical conditions like the reaction constant, half-life period, and the activation energy needed for degradation were determined. The activation energy is the minimum energy required to undergo a chemical reaction. To determine the effect of storage conditions on the kinetics of the degradation process, the constants $\left(k\right.$ and $\left.t_{1 / 2}\right)$ were fitted to an Arrhenius type equation as follows:

$$
k=K_{0} \mathrm{e}^{-\mathrm{Ea} / R T}
$$

where,

$$
\begin{aligned}
& \mathrm{Ea}=\text { the activation energy }(\mathrm{kJ} / \mathrm{mol}) \\
& K_{0}=\text { frequency factor }\left(\text { hour }^{-1}\right) \\
& R=\text { the universal gas constant }(8.314 \mathrm{~J} / \mathrm{mol} \cdot \mathrm{K}) \\
& T=\text { absolute temperature }(\mathrm{K})
\end{aligned}
$$

\section{RESULTS AND DISCUSSION}

\section{Optimization of solvent for anthocyanin extraction}

Absolute ethanol, ethanol acidified with hydrochloric acid, and citric acid at different ratios were used as a solvent for anthocyanin extraction and the results are presented in Table 1. 
Table 1. Quantification of total anthocyanin using different solvent as an extraction medium.

\begin{tabular}{lc}
\hline Solvent types & Total anthocyanin (mg/100 g) \\
\hline Absolute ethanol & 33.40286 \\
Absolute ethanol acidified with 1.5 N HCl & 165.6721 \\
Absolute ethanol acidified with 1 N HCl & 152.6426 \\
Absolute ethanol acidified with 1\% CA & 95.39886 \\
Absolute ethanol acidified with 2\% CA & 102.462 \\
\hline
\end{tabular}

Absolute ethanol acidified with $1.5 \mathrm{~N} \mathrm{HCl}$ released more pigment $(165.67 \mathrm{mg} / 100 \mathrm{~g})$ from the roselle calyces and $152.64 \mathrm{mg} / 100 \mathrm{~g}$ for that acidified with $1 \mathrm{~N} \mathrm{HCl}$. Absolute ethanol resulted in the lowest extraction value $(33.40 \mathrm{mg} / 100 \mathrm{~g})$.

\section{Optimization of roselle calyx to solvent ratio for extraction}

The highest value $(165.6721 \mathrm{mg} / 100 \mathrm{~g})$ from the optimized solvent type (absolute ethanol acidified with $1.5 \mathrm{~N}$ $\mathrm{HCl}$ ) was taken for further optimization. Then, absolute ethanol acidified with $1.5 \mathrm{~N} \mathrm{HCl}(85: 15)$ was added to the sample in the ratios of $1: 2,1: 3,1: 4,1: 5,1: 6$, and 1:7, respectively, and the results are shown in Figure 1(a). The maximum yield of pigment $185.17 \mathrm{mg} / 100 \mathrm{~g}$ was obtained for the material-to-solvent ratio of $1: 2$ and the yield decreased as the ratio increased from $1: 3$ to $1: 7$ from 164.63 to $93.88 \mathrm{mg} / 100 \mathrm{~g}$.

\section{Optimization of temperature for extraction}

Temperature plays a major role in the extraction of anthocyanin. The maximum temperature set was $60^{\circ} \mathrm{C}$ because anthocyanins are very heat sensitive and they start to degrade rapidly above $60^{\circ} \mathrm{C}$. It is observed from the table that the highest $(291.35 \mathrm{mg} / 100 \mathrm{~g})$ and the lowest $(218.74 \mathrm{mg} / 100 \mathrm{~g})$ recovery of anthocyanin were at $50^{\circ} \mathrm{C}$ and $30^{\circ} \mathrm{C}$, respectively. At a temperature of $30^{\circ} \mathrm{C}$, the reaction rate was slow but faster at $50^{\circ} \mathrm{C}$. The lower recovery at $60^{\circ} \mathrm{C}(237.18 \mathrm{mg} / 100 \mathrm{~g})$ is due to material degradation (Fig. 1b).

High temperature can increase compound solubility and diffusion and decrease the viscosity of solvents, thereby resulting in an improvement of the efficiency of the extraction (EscribanoBailon and Santos-Buelga, 2003). Nevertheless, anthocyanins are sensitive to heat and can easily convert to the colorless chalcone form during heating (Wrolstad et al., 2002).

\section{Optimization of time for anthocyanin extraction}

The extraction time of pigment is an important criterion which affects the quantity of pigment obtained. It is evident from Figure 1(c) that the highest quantity of extract $(344.67 \mathrm{mg} / 100 \mathrm{~g}$ ) was obtained at 45 minutes time. As time progresses, the extraction efficiency had also got decreased. Initially, the quantity of pigment extracted increased, and after 45 minutes it got decreased and yielded $217.25 \mathrm{mg} / 100 \mathrm{~g}$. (a)

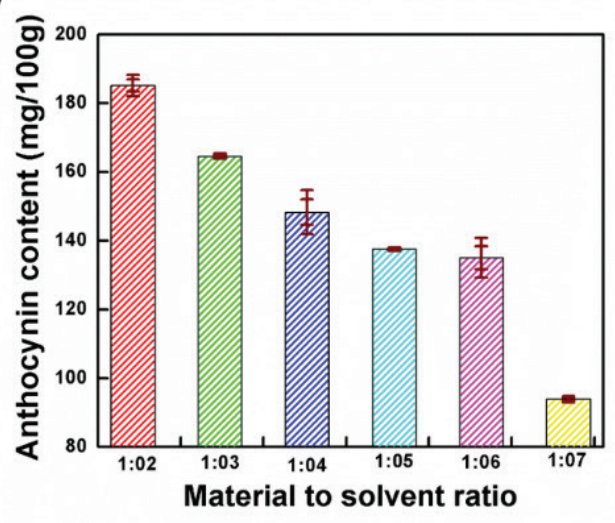

(b)

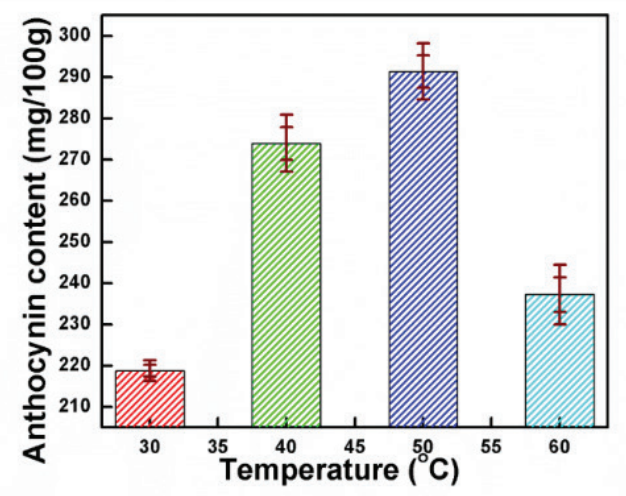

(c)

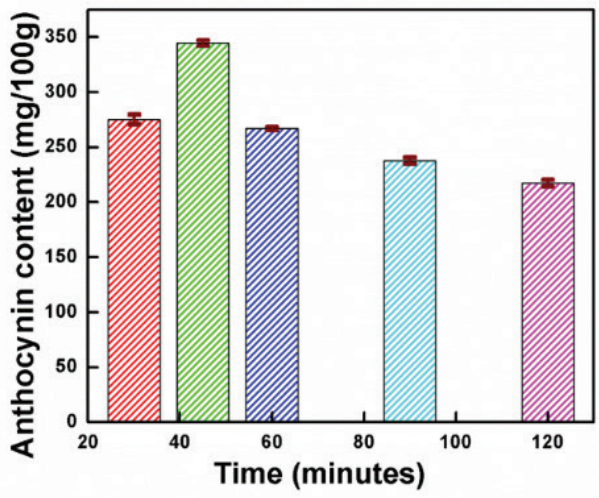

(d)

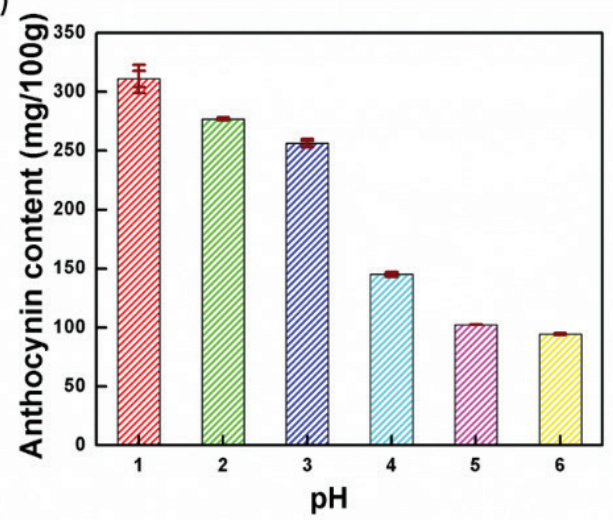

Figure 1. Optimization of anthocyanin pigment based on different factors of extraction. 
Anthocyanins normally occur in flower petals, fruits, stems, roots, and leaves, accumulating in vacuoles of epidermal and sub-epidermal cells (Strack and Wray, 1994). A short extraction time was not sufficient to allow solvents to penetrate deeply into particles and released efficiently other phenolics with more non-polarity rather than anthocyanins.

The presence of oxygen and interactions with other components, like sugars and ascorbic acid also affect anthocyanin stability. The main cause of pigment color loss seems to be related to anthocyanin hydrolysis due to the observed proportionality between the speed of red color disappearance from anthocyanins and the velocity of free sugar formation. Heat causes anthocyanins to degrade, which were found at $\mathrm{pH} 2.0-4.0$, to undergo hydrolysis at glycoside linkages to produce chalcone and later, alphadiketones (Adams, 1973).

\section{Optimization of pH for anthocyanin extraction}

The optimum $\mathrm{pH}$ value for the maximum yield of anthocyanin pigment was determined. The $\mathrm{pH}$ range was set between 1 and 6 . It was observed that with the increase of $\mathrm{pH}$, the anthocyanin content decreased. Acidic condition resulted in more anthocyanin yield than at higher $\mathrm{pH}$ (Fig. 1d).

Anthocyanins are sensitive to $\mathrm{pH}$ and undergo reversible transformations from acid to base environment due to the gain or loss of a proton: flavylium cation, carbinol pseudobase, colorless chalcone, and quinonoidal base. The flavylium cation, most abundant at the low $\mathrm{pH}$ condition, is the most stable form of those. Accordingly, acids are usually used in anthocyanin extraction because of the anthocyanin stability and increased polarity by the positive charge as well (Wrolstad et al., 2002).

\section{Determination of heat stability of anthocyanin}

The stability of anthocyanins and the rate of degradation are notably influenced by temperature. The stability of anthocyanin at different time and temperatures was studied and the results are given in Table 3. As the temperature and time increases, the percentage retention of anthocyanin decreases. The initial concentration was found to be $335.69 \mathrm{mg} / 100 \mathrm{~g}$. At $60^{\circ} \mathbf{C}$, 30 minutes exposure, a slight reduction $(1.07 \%)$ in pigment was observed $(332.10 \mathrm{mg} / 100 \mathrm{~g})$. Further increase in time decreased the pigment content to $296.21 \mathrm{mg} / 100 \mathrm{~g}(88.24 \%)$. At $100^{\circ} \mathbf{C}$, 30 minutes exposure, the pigment concentration attained 247.01 $\mathrm{mg} / 100 \mathrm{~g}(76.62 \%)$ and $142.39 \mathrm{mg} / 100 \mathrm{~g}(44.17 \%)$ at the end of 90 minutes. It was observed that anthocyanin showed relatively high stability at a lower temperature and particularly when the heating period was relatively short (30-45 minutes). The results are in line with the results obtained by Abyari et al. (2006).

Palamidis and Markakis (1975) studied the effect of temperature on the stability of anthocyanin in soft drinks and have shown that an increase in the storage temperature gradually accelerate the destruction of pigments in soft drinks. Spayd et al. (2001) found that the increase in temperature accelerated the destruction of anthocyanins. Chaiyasut et al. (2018) proved that the storage temperature had a greater influence on the phenolic content in the products.

\section{Kinetic study of pigment under different storage conditions}

The degradation of anthocyanin pigment during storage using amber and transparent bottles under different conditions (refrigerated, dark, and luminescent room) was analyzed.

The aqueous anthocyanins contents from roselle calyces during storage were plotted as a function of time (Figs. 2-7). The linear regression of the total anthocyanins content during storage confirmed that degradation followed first-order reaction ki'netics. The obtained results are in agreement with those from the previous studies which showed that storage degradation of anthocyanins from various sources was described by first-order reaction kinetics (Kirca et al., 2007; Moldovan et al., 2012; Sipahli et al., 2017; Wang and $\mathrm{Xu}, 2007)$.

The kinetic parameters of degradation of anthocyanins from roselle calyces extract at different conditions are provided in Table 4. The results revealed that the least reaction rate ( $k$ value 0.0017$)$ was observed for amber bottles under a refrigerated condition with a maximum half-life $\left(t_{1 / 2}\right)$ of 407.73 days. Among all the conditions,

Table 2. Retention of anthocyanin after heat treatment.

\begin{tabular}{|c|c|c|c|c|c|c|}
\hline \multirow{2}{*}{ Treatment temperature $\left({ }^{\circ} \mathrm{C}\right)$} & \multicolumn{6}{|c|}{ Duration of exposure of anthocyanin (minute) } \\
\hline & $\mathbf{0}$ & 30 & 45 & 60 & 75 & 90 \\
\hline 60 & $335.69(100 \%)$ & $332.10(98.93 \%)$ & $323.04(96.23 \%)$ & $312.26(93.02 \%)$ & $307.59(91.63 \%)$ & $296.21(88.24 \%)$ \\
\hline 70 & $335.69(100 \%)$ & $329.45(98.14 \%)$ & $313.57(93.41 \%)$ & $286.71(85.41 \%)$ & $261.27(77.83 \%)$ & $230.92(68.79 \%)$ \\
\hline 80 & $335.69(100 \%)$ & $304.39(93.23 \%)$ & $289.44(88.65 \%)$ & $259.95(79.62 \%)$ & $226.88(69.49 \%)$ & $201.22(61.63 \%)$ \\
\hline 90 & $335.69(100 \%)$ & $278.99(85.45 \%)$ & $255.45(78.24 \%)$ & $227.70(69.74 \%)$ & $197.46(60.48 \%)$ & $180.68(55.34 \%)$ \\
\hline
\end{tabular}

Table 3. Kinetic parameters of degradation of anthocyanins from roselle calyces extract at different conditions.

\begin{tabular}{llcc}
\hline Storage conditions & Storage container & $\boldsymbol{K}$ (reaction constant), $\mathbf{h}^{-1}$ & $\boldsymbol{t}_{1 / 2}(\mathbf{d a y s})$ \\
\hline \multirow{2}{*}{ Refrigerated } & Amber colored bottle & $0.0017(0.9797)^{*}$ & 407.7336 \\
& Transparent bottle & $0.0025(0.967)^{*}$ & 277.2589 \\
\multirow{2}{*}{ Dark room $\left(40^{\circ} \mathrm{C}\right)$} & Amber colored bottle & $0.0031(0.951)^{*}$ & 223.5959 \\
& Transparent bottle & $0.005(0.940)^{*}$ & 138.6294 \\
Luminance $\left(40^{\circ} \mathrm{C}\right)$ & Amber colored bottle & $0.0047(0.984)^{*}$ & 147.4781 \\
& Transparent bottle & $0.0055(0.989)^{*}$ & 126.0268 \\
\hline
\end{tabular}




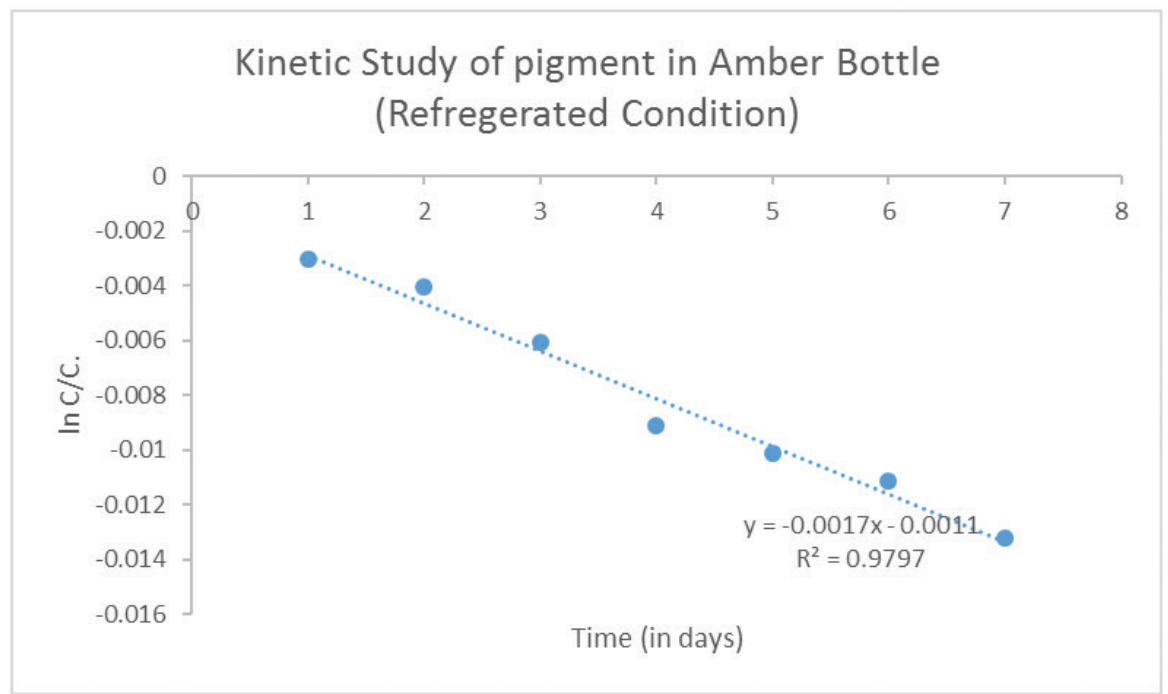

Figure 2. Kinetic study of pigment stored in an amber colored bottle under refrigerated condition.

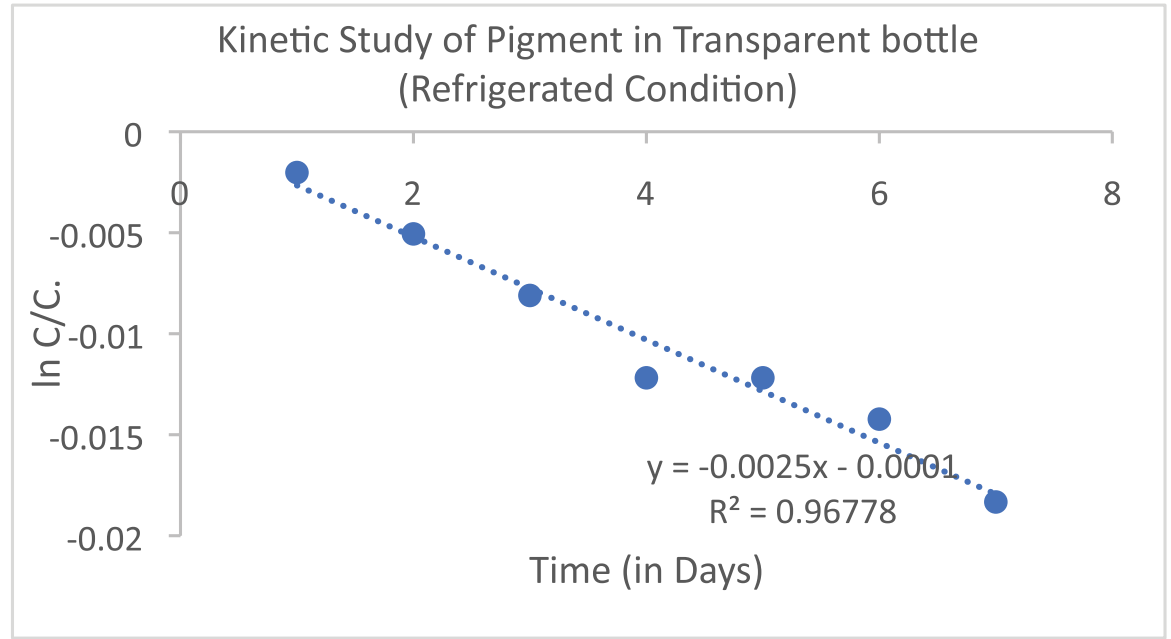

Figure 3. Kinetic study of pigment in a transparent bottle under refrigerated condition.

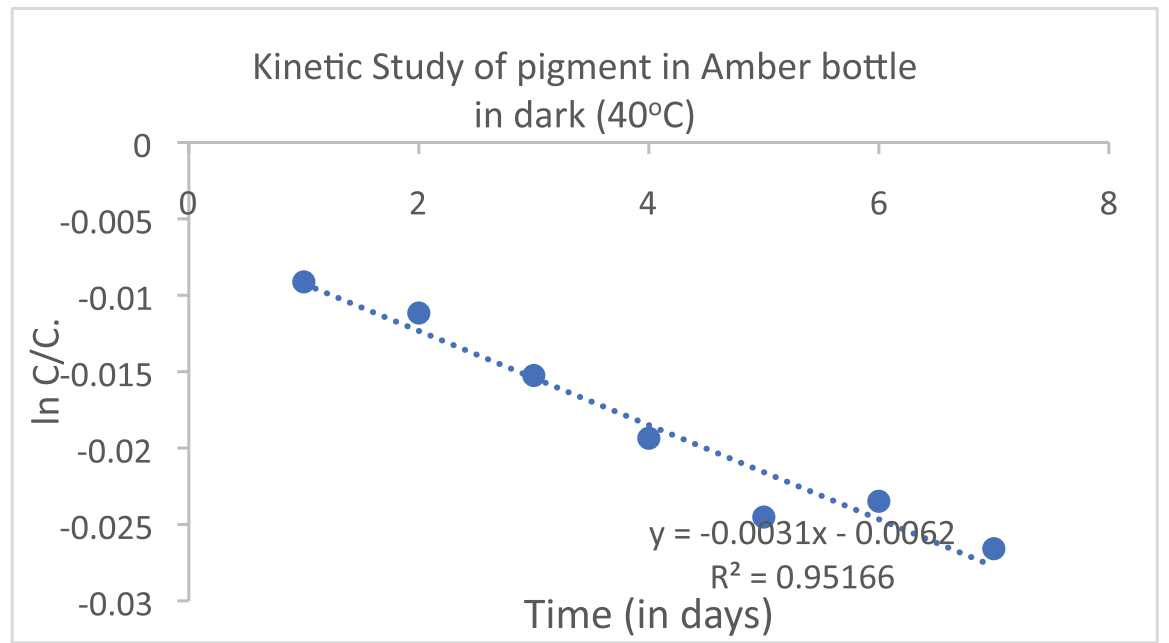

Figure 4. Kinetic study of pigment in an amber bottle in dark $\left(40^{\circ} \mathrm{C}\right)$. 


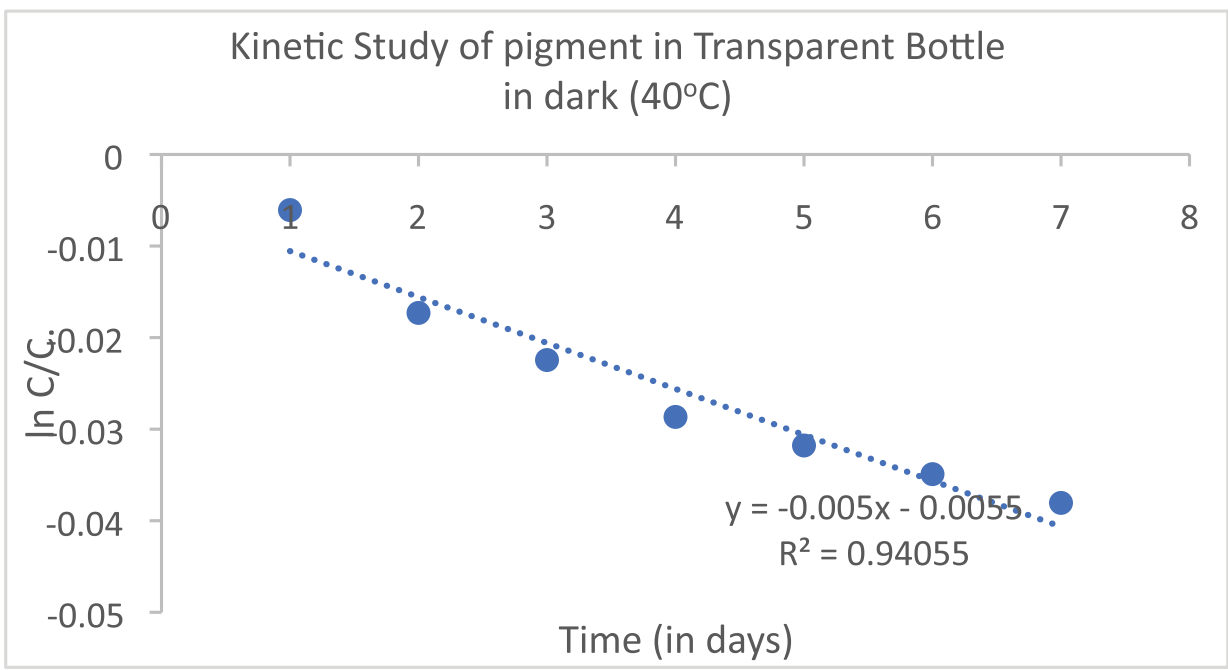

Figure 5. Kinetic study of pigment in a transparent bottle in dark $\left(40^{\circ} \mathrm{C}\right)$.

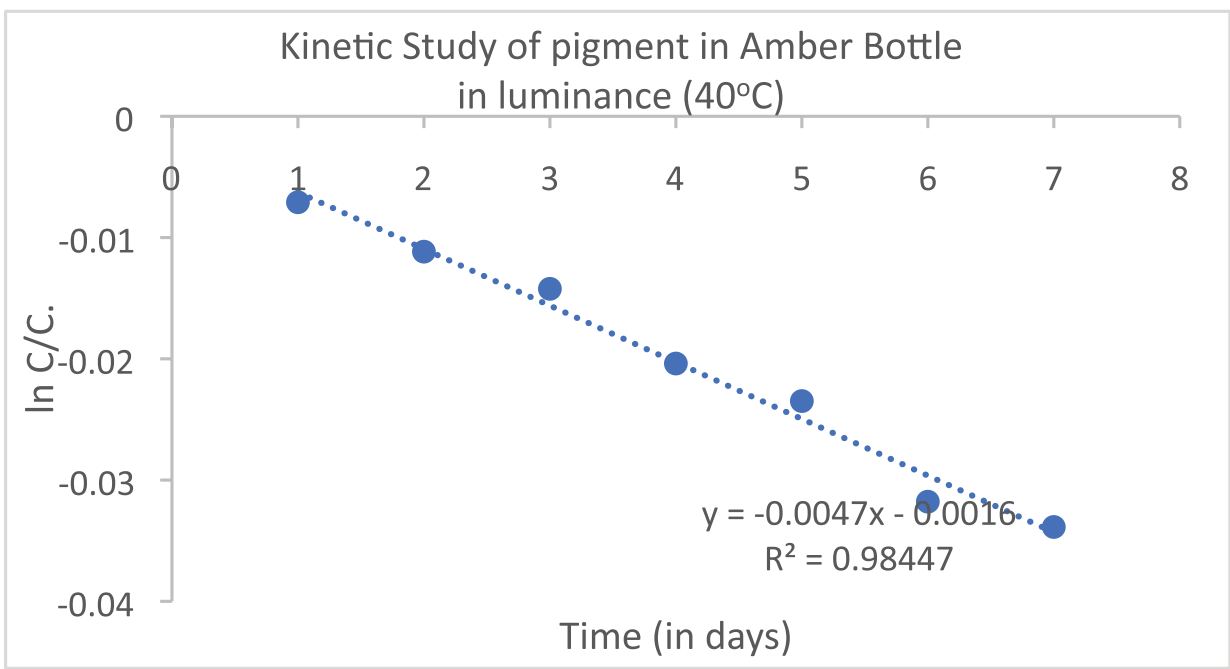

Figure 6. Kinetic study of pigment in an amber bottle in luminance $\left(40^{\circ} \mathrm{C}\right)$.

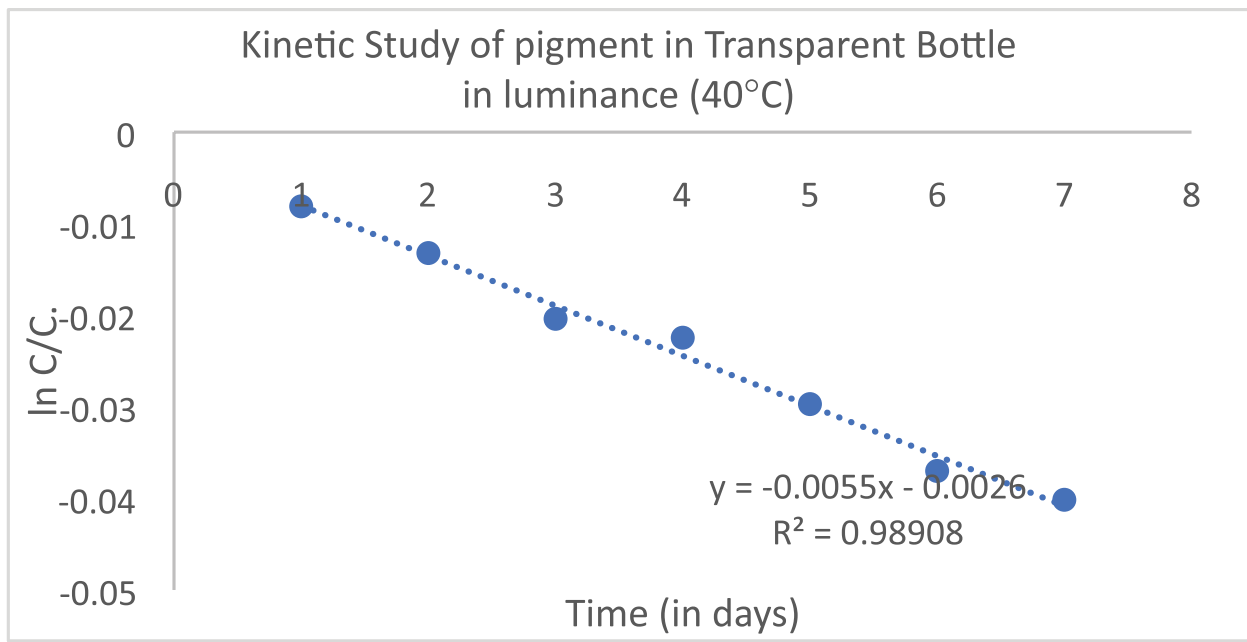

Figure 7. Kinetic study of pigment in a transparent bottle in luminance $\left(40^{\circ} \mathrm{C}\right)$. 
Table 4. Tabulation for $\ln k$ and $1 / T_{\mathrm{a}}$.

\begin{tabular}{cccccc}
\hline $\begin{array}{c}\text { Type of Container } \\
\text { (bottle) }\end{array}$ & Type of treatment & $\boldsymbol{k}$ values & $\ln \boldsymbol{k}$ & $\begin{array}{c}\text { Absolute temperature }(\boldsymbol{t}+\mathbf{2 7 3}) \\
\left(\boldsymbol{T}_{\mathrm{a}}\right)\end{array}$ & $\mathbf{1 / \text { temperature } ( \mathbf { 1 } / \boldsymbol { T } _ { \mathrm { a } } )}$ \\
\hline Amber & Refrigerated $\left(4^{\circ} \mathrm{C}\right)$ & 0.0017 & -6.3771 & 277 & 0.00361 \\
Transparent & Refrigerated $(4)$ & 0.0025 & -5.9915 & 277 & 0.00361 \\
Amber & $40^{\circ} \mathrm{C}$ in dark & 0.0031 & -5.7764 & 313 & 0.003195 \\
Transparent & $40^{\circ} \mathrm{C}$ in dark & 0.005 & -5.2983 & 313 & 0.003195 \\
Amber & $40^{\circ} \mathrm{C}$ under luminescence & 0.0047 & -5.3602 & 313 & 0.003195 \\
Transparent & $40^{\circ} \mathrm{C}$ under luminescence & 0.0055 & -5.203 & 313 & 0.003195 \\
\hline
\end{tabular}

the highest rate constant was 0.0055 and has a least half-life $\left(t_{1 / 2}\right)$ of 126.02 days. By increasing the storage temperature from $4^{\circ} \mathrm{C}$ to $40^{\circ} \mathrm{C}$, the degradation rate constant, $k$, had increased by $1.5-3.3$ folds. The degradation constant was lowest under the refrigerated condition, which indicates the color stability (Zori et al., 2014).

\section{Activation energy}

Activation energy is the minimum energy required to undergo a chemical reaction. The energy needed to proceed the degradation of anthocyanin was calculated and represented in Table 4.

To determine the effect of storage conditions on the kinetics of the degradation process, the constants $\left(k\right.$ and $\left.t_{1 / 2}\right)$ were fitted to an Arrhenius type equation. The activation energy for the degradation of roselle calyces anthocyanin was estimated to be $15.5 \mathrm{kcal} / \mathrm{mol}$.

\section{CONCLUSIONS}

Hibiscus sabdariffa (roselle) is a tropical plant which can be used as food and fiber. The roselle calyxes are also widely used for the extraction of color as a food additive. The study aimed at the extraction of anthocyanin from the roselle calyxes using acidified ethanol as a solvent. It was found that absolute ethanol acidified with $1.5 \mathrm{~N} \mathrm{HCl}$ in the calyx-to-solvent ratio of 1:2, extracted for 45 minutes at $50^{\circ} \mathrm{C}$ under $\mathrm{pH} 1$ gave the highest anthocyanin extract of $335 \mathrm{mg} / 100 \mathrm{~g}$ than any other combinations of physical factors. Thermal stability test concluded that very less significant loss was observed when heated at $60^{\circ} \mathrm{C}$ for 30 minutes. Anthocyanins have relatively high stability at a lower temperature and particularly when the heating period was relatively short (30-45 minutes). The kinetic study of the pigment showed that the pigments, when stored in amber containers under refrigerated conditions, gave the least reaction rate and high half-life. The activation energy of the whole kinetic reaction was found to be $15.5 \mathrm{kcal} / \mathrm{mol}$.

\section{REFERENCES} $1973 ; 4: 19-20$

Adams JB. Colour stability of red fruit. Food Manufacture,

Borras-Linares I, Fernandez-Arroyo S, Arraez-Roman D, Palmeros-Suárez PA, Val-Díaz RD, Andrade-Gonzales I. Characterization of phenolic compounds, anthocyanidin, antioxidant and antimicrobial activity of 25 varieties of Mexican Roselle (Hibiscus sabdariffa). Ind Crops Prod, 2015; 69:385-94.

Chaiyasut C, Kesika P, Sakdakampanat P, Peerajan S, Sivamaruthi BS. Formulation and evaluation of stability of Thai purple rice bran based cosmetic products. Asian J Pharm Clin Res, 2018; 11(2):99-104.

$\mathrm{Du}$ CT, Francis FJ. Anthocyanins of roselle (Hibiscus sabdariffa L.). J Food Sci, 1973; 38:810-2.

Escribano-Bailon MT, Santos-Buelga C. Ch1. Polyphenol extraction from foods. In: Santos-Buelga C, Williamson G (eds.). Methods in polyphenol analysis. The Royal Society of Chemistry, Cambridge, UK, p 2, 2003 .

Kirca A, Cemeroglu B. Degradation kinetics of anthocyanins in blood orange juice and concentrate. Food Chem, 2003; 81(4):583-7.

Kirca A, Ozkan M, Cemeroğlu B. Effects of temperature, solid content and $\mathrm{pH}$ on the stability of black carrot anthocyanins. Food Chem, 2007; 101:212-8.

Abyari M, Heidari R, Jamei R. The effect of Heating, UV Irradiation and $\mathrm{pH}$ on stability of Siahe Sardasht grape anthocyanincopigment complex. J Biol Sci, 2006; 6(4):638-45.

Moldovan B, David L, Chisbora C, Cimpoiu C. Degradation kinetics of anthocyanins from European Cranberrybush (Viburnum opulus L.) fruit extracts. Effects of temperature, $\mathrm{pH}$ and storage solvent. Molecules, 2012; 17(10):11655-66. $1975 ; 40: 104$

Palamidis N, Markakis T. Structure of anthocyanin. Food Sci,

Patel S. Hibiscus sabdariffa: an ideal yet under-exploited candidate for nutraceutical applications. Biomed Prev Nutr, 2014; 4(1):23-7.

Peleg M, Kim AD, Normand MD. Predicting anthocyanins' isothermal and non-isothermal degradation with the endpoints method. Food Chem, 2015; 187:537-44.

Plotto A, Mazaud F, Röttger A, Steffel K. HIBISCUS: postproduction management for improved market access. In: Mazaud $\mathrm{F}$, Röttger A, Steffel K (eds.). INPhO_post-harvest compendium. Food and Agriculture Organization of the United Nations (FAO), Rome, Italy, pp $1-19,2004$.

Sipahli S, Mdhanlall V, Mellem JJ. Stability and degradation kinetics of crude anthocyanin extracts from $H$. sabdariffa. Food Sci Technol Campinas, 2017; 37(2):209-15.

Spayd SE, Tarara JM, Mee DL, Feguson JC. Separation of sunlight and temperature effects on the composition of Vitis vinifera. J Food Sci, 2002; 53:3.

Strack D, Wray V. The anthocyanins. In: Harborne JB (ed.). The flavonoids: advances in research since 1986. 1st edition, Chapman \& Hall, New York, NY, pp. 1-22, 1994.

Wang WD, Xu SY. Degradation kinetics of anthocyanins in black berry juice concentrate. J Food Eng, 2007; 82(3):271-5.

Wrolstad RE, Durst RW, Giusti MM, Rodriguez-Saona LE. Ch. 4 analysis of anthocyanins in nutraceuticals. In: Ho CT, Zheng QY (eds.). Quality management of nutraceuticals. Am Chem Soc, Washington, DC, pp 42-62, 2002.

Zori Z, Dragovi-Uzelac V, Pedisi S, Kurtanjek Z, Garofuli IE. Kinetics of the degradation of anthocyanins, phenolic acids and flavonols during heat treatments of freeze-dried sour cherry marasca paste. Food Technol Biotechnol, 2014; 52(1):101-8.

How to cite this article:

Pragalyaashree MM, Tiroutchelvame D, Sashikumar S. Degradation Kinetics of Anthocyanin extracted from roselle calyces (Hibiscus sabdariffa). J App Pharm Sci, 2018; 8(11): 057-063. 